\title{
DIGITAL CHANGE AND MARGINALIZED COMMUNITIES: CHANGING ATTITUDES TOWARDS DIGITAL MEDIA IN THE MARGINS
}

\author{
Gen Eickers ${ }^{1}$, Matthias Rath ${ }^{2}$ \\ ${ }^{1}$ Ludwigsburg University of Education (GERMANY) \\ ${ }^{2}$ Ludwigsburg University of Education (GERMANY)
}

\begin{abstract}
Marginalized communities are confronted with issues resulting from their marginalization, such as exclusion, invisibility, misrepresentation, and hate speech, not only offline but - due to digital change - increasingly online. Our research project DigitalDialog21 aims at evaluating the effects of digital change on society and how digital change, and the risks and possibilities that come with it, is perceived by the population. Digital change is understood as a factor of social change in this project. By investigating digital change and its effects on society, we are able to draw more general inferences on how societies change socially and what needs to be done in education to establish digital trust.

In 2017 the Digital Evolution Index observed an increasing trust deficit and skepticism towards digitalization in both very industrialized and lesser industrialized countries. We will draw inferences from these observations here and hypothesize the following: It seems that especially in marginalized communities, that is: in communities that are structurally and systemically disadvantaged and that experience societal marginalization, this trust deficit and skepticism towards digitalization is prevalent. This could be so because, as a member of a marginalized community, one might quickly find issues resulting from marginalization to be present in digital spaces just like they are present in non-digital spaces.

This paper will examine critically how attitudes in marginalized communities towards digital media are influenced by digital change. Do the risks of digitalization outweigh the advantages for marginalized communities? Are digital media perceived to provide advantages such as increased visibility and representation or are they perceived to fuel discrimination against marginalized people? Our research project brings together secondary analyses of existing studies with the results of our own qualitative interview study on marginalized people's perceptions of digital change. The paper will portray some example interviews, and thereby analyze if and how attitudes in the margins towards digital media change, what this change consists of, and how we can understand the changing attitudes within an ethical and educational framework.

Our findings will point at a necessity to increase ethically based digital literacy (PEAT) in the German education system, starting in early education. Marginalized groups in particular must be empowered to become digitally competent through problem-oriented education. Independent self-efficacy can increase digital trust in fragmented societies. The paper concludes by introducing media ethics tools that are being developed as part of the project.
\end{abstract}

Keywords: digital change, marginalization, media ethics, digital media, digital literacy 
Appears in: ICERI2021 Proceedings, https://doi.org/10.21125/iceri.2021.1197

\section{INTRODUCTION}

„I think digital media can help distribute marginalized perspectives. But I wonder if it reaches people outside certain bubbles, people who are not marginalized in any way, and people who might even actively discriminate against marginalized folks?" - $\mathrm{B}^{1}$

$\mathrm{B}$, a queer and non-binary individual, harbors a lot of skepticism towards digital media. Mostly, that skepticism derives from the fact that they witness a willingness for digital exchange and education around marginal topics inside their queer social bubble, but not outside of it. As a result, B recognizes the possibilities digital media offers and digital change brings about, but nevertheless experiences digital change as limited and restrictive and, due to their marginalization, is only able to enjoy digital media with caution.

Marginalized communities are confronted with issues resulting from their marginalization, such as exclusion, invisibility, misrepresentation, and hate speech, not only offline but - due to digital change increasingly online.

This paper will examine critically how attitudes in marginalized communities towards digital media are influenced by digital change. Do the risks of digitalization outweigh the advantages for marginalized communities? Are digital media perceived to provide advantages such as increased visibility and representation or are they perceived to fuel discrimination against marginalized people? Our research project brings together secondary analyses of existing studies with the results of our own qualitative interview study on marginalized people's perceptions of digital change. The paper will portray some example interviews, and thereby analyze if and how attitudes in the margins towards digital media change, what this change consists of, and how we can understand the changing attitudes within an ethical and educational framework.

Our findings will point at a necessity to increase ethically based digital literacy (PEAT) in the German education system, starting in early education. Marginalized groups in particular need to be empowered to acquire digital competency. The paper concludes by introducing media ethics tools that might help individuals develop digital competency.

\section{DIGITAL CHANGE}

Digitalization is a fairly recent phenomenon. The beginning of digitalization is marked by a communicative innovation that has been technically complete since the 1970s but that has not been used broadly until the late 1980s: the Internet. The World Wide Web (WWW), developed in 1990 [1], presents a new medial representation of the world that complements and absorbs all previous medial representations [2].

Dietrich Kerlen (2005, p. 42) speaks of a specific "media moralization" in Germany. In his culturalhistorical study about youth and media in Germany, he was able to show that all non-book media are considered culturally inferior and pedagogically suspect [3]. Media skepticism since the 19th century brought together different ideologies united by the standard view that only the analog book is an appropriate form of information, education, entertainment and advice. This media skepticism gained particular momentum with the incursion of the digital into the media ensemble. This morally charged media skepticism has led to a profound distrust of digital change in Germany [4]. Elsewhere we have already described this peculiarity of German media reception [5].

Our study presented here is part of the more extensive research program "Digitaldialog 21" on digital change. ${ }^{2}$ Our research project DigitalDialog21 aims to evaluate the impact of digital change on society and investigate how digital change and the associated risks and opportunities are perceived by the population. In this project, digital change is understood as a factor of social change. By examining digital change and its impact on society, we can draw broader conclusions about how societies are changing and

${ }^{1}$ All names in this study have been changed to protect confidentiality.

2 Three German universities are involved in this project: Furtwangen University of Applied Sciences, Stuttgart Media University, and Ludwigsburg University of Education. The interdisciplinary research group combines socioinformatics, sociology, education, philosophy, communication, and media studies. The empirical research focuses on quantitative surveys with questionnaires and qualitative methods such as narrative interviews and in-depth interviews. 
what needs to be done in education to build digital confidence. The program aims to capture public awareness about digitalization and seek ways to encourage reflection on the importance of individual practice for digital change. On the one hand, we observe a skeptical attitude of Germans towards digital change but, on the other hand, digital change is the result of media practice. Analyzing the connection between media practice and skeptical attitudes towards digital change is important in order to provide a reliable depiction of society's interplay with digital change. The project not only surveys the population's attitudes toward digital change but also seeks active participation of the population in dialogues about the research results.

Our project group is primarily concerned with philosophical-ethical and media pedagogical implications of digital change. We focus on the practice of digital communication and its framework for marginalized groups. The buzzword "digital divide" has been used to examine unequal access to digital communication opportunities since the 1990s [6]. "The digital divide commonly refers to the gap between those who do and those who do not have access to new forms of information technology" [7]. To date, the focus has primarily been on economic, technical, or other aspects such as disability that impede access [8] [9]. However, attitudinal and social aspects have also increasingly been acknowledged [7].

In marginalized groups, we can observe a "media invisibility" [10]. With the practical expansion of media practice [11], the question for marginalized groups is whether the use of digital means of communication is seen as an additional impairment or as an opportunity to step out of this media invisibility. The empirical description and normative-ethical analysis together form the theoretical framework for formulating demands for a comprehensive digital education that aims at decreasing marginalization.

\section{MARGINALIZATION \\ 3.1 What is marginalization?}

Marginalization can be understood as being forced to be in the peripheries of society. It comes with limited access and opportunities to political, social, and economic goods.

Originally used to describe experiences of immigration [12], according to which marginalization means a "lack of integration and the status as an "outsider" with respect to dominant cultures" [13], the concept of marginalization is now applied to a broader range of phenomena, addressing cultural, social, and structural forms of being (nearly) excluded. According to Fricker, for example, the exclusion takes place as exclusion from valuable practices [14]. Billson (2005) identifies different kinds of marginalization, referring to cultural processes, to social roles, and to social structures more broadly [15].

\subsection{How does marginalization take place digitally?}

The concept of digital marginalization is typically concerned with people who do not have or use the internet [16] [17] [18], people who lack access to fast and reliable internet connection (e.g., people living in rural areas [18] [19]), and people who lack the skills or the access to developing skills for using the internet [20] [21] [22].

But digital marginalization goes further than affecting those with limited access and limited skills; the concept extends to a social dimension. That is, digital marginalization also concerns the reproduction of marginality in digital spaces such as social media.

Sharing content on digital media goes hand in hand with communicating social and moral values and political attitudes. For example, by sharing a photo of a flower on digital media while everyone one is digitally connected with shares election results, one may communicate one's disinterest in politics or one's belief in a better political future. Digital interactions contribute to making arguments and values more accessible (depending on the audience reached). However, this opportunity is also fraught with risks, especially regarding marginalized identities.

As argued in earlier work [5], marginalized groups are especially vulnerable to the negative effects of digital change. For marginalized identities, engaging on and with digital media often means facing further marginalization [23].

Reports describing the discrimination of marginalized identities in digital media by other users but also by the very policies of the respective digital media are on the rise. ${ }^{3}$ Consider for example restrictions on

\footnotetext{
${ }^{3}$ For example, see:
} 
Facebook and Instagram concerning the kinds of bodies portrayed [24] [25]. Consider also rules requiring users to provide their name as given in their passport or actual photos on digital media, thereby putting LGBTQ+ users, for example, at risk of being involuntarily outed. ${ }^{4}$ Such regulations present obstacles to marginalized identities and thereby further contribute to marginalization.

As mentioned, the presence of online hate speech that targets marginalized identities directly also fuels digital marginalization. Hate speech directed at trans people on social media, for example, is on the rise. ${ }^{5}$ Data recording acts of violence in the offline world show a dramatic increase in transphobic attacks and suggest a connection between online and offline transphobia. In England, Scotland, and Wales, acts of violence against trans people, for example, increased by $81 \%$ compared to the data collection period 2018-19 to 2016-17. ${ }^{6}$

\section{CHANGING ATTITUDES TOWARDS DIGITAL MEDIA IN THE MARGINS}

Experiences with digital marginalization contribute to fostering skeptical attitudes and a trust deficit towards digital change in marginalized communities. It is inevitable to consider the attitudes of marginalized groups when researching digital change in order to evaluate digital change as a whole and in order to be able to develop tools to deal with experiences of digital marginalization and the negative effects of digitalization in general.

\subsection{Example: attitudes of Igbtq+ people ${ }^{7}$}

In what follows, we will focus on the digital media experiences of Igbtq + individuals in order to provide a more detailed analysis of the changing attitudes of marginalized communities towards digital change. We will portray example interviews, analyze if and how attitudes in the margins towards digital media change, what this change consists of, and how we can understand the changing attitudes within an ethical and educational framework. We will not provide an overarching analysis of the interviews conducted in this paper but, rather, focus on some examples and the specific questions we just mentioned. In general, the interviews show that Igbtq + people tend to harbor skepticism towards digital change while also relying heavily on digital media and acknowledging the importance of digital and especially social media for their lives. Let us look at some examples:

Rob, a 40-year-old gay cis man, speaks about the reproduction of hate and discrimination against lgbtq+ people in online spaces: „I think you are more easily exposed to rejection and hatred than 10 years ago. This is reflected in the messages I get on social media; it's absurd to see that kind of hatred spelled out in written words." Rob compares his experiences on social media now with his experiences on social media ten years ago.

He says he does not think that social behavior on social media has gotten better with increasing digitization; that is, he does not perceive a reduction of discrimination against Igbtq+ people in online spaces. Rather, he perceives the hate and discrimination happening to Igbtq + people online now as more severe and more frequent than the hate and discrimination against lgbtq + people online ten to fifteen years ago. „Back then it was at least people with faces who said they thought I sucked. I have quite a lot of trans friends, with whom I also talk about such things from time to time. There are different words being used when they are facing discrimination, but they are of the same quality. But that has now been shifted from the street to online spaces. That's how I feel about it. (...) It's a shame because online spaces were often spaces where I could be who I am... and now I can neither do that online nor on the streets. (...) It's

- "Risks of Discrimination through the Use of Algorithsm":

https://www.antidiskriminierungsstelle.de/EN/homepage/ documents/download diskr risiken ver wendung von algorithmen.pdf? blob=publicationFile\&v=1

- "Online racial discrimination: A growing problem for adolescents": https://www.apa.org/science/about/psa/2015/12/online-racial-discrimination

4 See "Social Media Putting LGBT Communities at Risk: Facebook": https://www.humanrightsfirst.org/blog/social-media-putting-lgbt-communities-risk-facebook

${ }^{5}$ See a study on transphobia on social media here: https://www.brandwatch.com/reports/transphobia/

6"Transgender hate crimes recorded by police go up 81\%": https://www.bbc.com/news/uk-48756370

${ }^{7}$ Igbtq+: lesbian, gay, trans, queer, + (other marginalized identities along sexual and gender identity spectra) 
a shame that this room is being lost." Rob articulates his worry that the safety of online spaces for lgbtq+ people is decreasing because of the increase in online discrimination against Igbtq + people. He is especially skeptical about the increase of anonymity and the lack of data protection that, he worries, is being used and instrumentalized for discriminating against marginalized people online. Other people we interviewed mentioned similar worries but also pointed to other issues they see with digital change.

Neka, a 25-year-old trans and queer person, talks about connecting with other trans and queer people online. Neka told us that they registered on Instagram when they were about to move out from their parents' place and that they slowly realized how important such online spaces are for connecting with people who are part of the same communities. Even though they acknowledge the importance for community-building, Neka also describes feeling a certain kind of distress with Instagram: „I'm very ambivalent about Instagram. It kind of annoys me. On a regular basis, I'm thinking about deleting it because it is kind of stressful, but it is also such a practical tool for exchanging information. You can learn a lot and you have access to so much information - also from queer people all over the world. Also, if a person gets attacked or has financial issues, the information spreads quickly in the online community - so you can ask the community for support or even money when something happens. (...) I think l'd miss a lot if I wasn't there. Like, I wouldn't hear about things that are important to hear about. And also to share resources and responsibility." Neka finds themself in a dilemma: on the one hand, they describe being annoyed and stressed by social media, on the other hand they are not sure the community they are part of would exist the way it does now without social media. Despite having some negative feelings about social media, and thereby about digital change, Neka sees a lot of opportunities for lgbtq + people coming about with being digitally connected: they mention the exchange of information, news about things happening in the community, and they talk about social media as an important tool for being able to provide support to individuals in a marginalized community.

Paula is a lesbian cis woman who talks about the issues surrounding digital change she sees internal to Igbtq + communities. For example, she criticizes the high expectations lgbtq + people on social media seem to have of each other: Paula describes expectations about being politically outspoken about your own and other marginalized group's rights. Often, she says, the communities will consider it a problem if you do not use your social media account to post the current political content everyone posts about. „When I'm an active women's rights activist, everyone on social media expects me to know about everything remotely related to feminism. Unfortunately, I can't know everything, I have a limited brain capacity and a limited posting capacity and limited internet capacity. This also creates (...) a fear of expressing oneself, because whatever you say will be denounced within the next two hours anyway. That is something that everyone feels and that everyone seems disgusted by but also something in which everyone participates anyway. I think if I talked to friends about it privately, they would agree, but they still participate. And that's how it comes about. (...) So, people post stuff like that on Instagram (...) but who would dare to come to me in real life and throw these expectations at me?" Here we can see how social media and the way they're being used in marginalized communities create a pressure to conform to certain behavioral expectations within those communities. Paula describes perceiving a discrepancy between expectations about offline behavior and expectations about online behavior.

The interviews portrayed here show a rather broad range of thoughts and concerns lgbtq+ individuals have regarding social media and thereby regarding digital change. There are concerns about harassment, about being criticized for using social media for the wrong purposes, and about becoming too dependent on social media. It becomes apparent that all interviewed participants harbor skeptical attitudes towards digital change, particularly towards how social media and its usage has developed.

\section{ETHICAL IMPLICATIONS: the necessity to increase digital literacy}

Questions about the normative evaluation of digital change focusing on marginalized identities and their opportunities and risks in and through digital change are ethically relevant. The results of our project will support professional media educators in gaining an argumentatively balanced view on media and digital change [26]. Furthermore, the project's pedagogical goal is to develop practical tools that help to come to an ethically sound assessment of digital offerings on an individual and non-professional level, beyond schools and for all age groups [27].

What are the conclusions that can be drawn from the exemplary interviews presented here? Digital communication is also experienced ambivalently in other marginalized groups [28] [29]. Attacks, insults, and overreactions to marginalized people and people with a different way of life, opinion, or group affiliation are widely represented. The willingness to take responsibility for one's own communication 
Appears in: ICERI2021 Proceedings, https://doi.org/10.21125/iceri.2021.1197

decreases in the context of increasingly anonymized digital communication [30]. However, the particular marginalizations of our interviewees feeds into their perception of social media and of digital change. Digital experiences, thus, seem inseparable from social identities and marginalizations.

It is also noticeable that our interviewees have high hopes for digital communication - in some cases, more than previous experiences would justify. The "trust surplus" -"there is a mismatch between the quality of the digital experience and environment and the users' levels of tolerance for friction" [31] - is fed by negative non-digital communication and the explicit recognition of the potential of digital communication [32]. In particular, our interviewee "Neka" is a good example of this experience-driven optimism. These high hopes, however, also facilitate disappointment: it seems that digital media are perceived to be an inevitable tool for marginalized communities to connect but they often disappoint because of their inability to provide protection from harassment or intra-community issues.

A key element to address the issue of protection from harassment and also to address further concerns surrounding data protection and online behavior is to increase digital literacy. This can and should be approached in public education, for example at schools.

The media skepticism that teachers in Germany in particular harbor [33] might be approached through positive experiences in pedagogical settings such as the classroom. Such an approach must be integrated into a pedagogical effort to reduce marginalization. Media education work to build digital trust can be subsumed under the goal of inclusive and media-friendly teaching [34]. There are two normative demands that are associated with this. Both are to be addressed above all at schools and specifically through the teaching staff. First, teachers need to become more familiar with technical mediatization [35]. Digital communication, especially when it goes beyond receptive media use, must be accompanied pedagogically to understand the social consequences of digitalization. Second, teachers must represent ethical positions independent of their specific subjects and apply them to practical issues; in this case to digital communication. There are different concepts that integrate technical and pedagogical or technical, pedagogical, and media aspects in teaching [36] [37].But equipping teachers with an awareness to diversity and inclusion additionally requires a normative orientation mediated by arguments [38]. Thus, technical skills, pedagogical skills, and individual attitudes need to be supported by normative ethics that enable teachers to identify problem areas of digital media use and communicate them through argument [34]. To this end, reference should be made here to another current model as a foil for integrating technical, pedagogical, media, and ethical aspects in classroom work on digitalization and marginalization. The Erasmus+ funded project Developing Student Teachers' Digital Competence DICTE (https://dicte.oslomet.no/) has pointed out that the conceptual basis for a common understanding of digital media use is far from being in place among educational authorities. McGarr and McDonagh, therefore, aim to provide teachers with a very condensed orientation, particularly in terms of their competencies and students' competencies in the areas of technology $(T)$, pedagogy $(P)$, attitudes $(A)$, and especially ethics (E). The PEAT model [39] explicitly focuses on the normative consequences of digital development at the micro-level of professionalized actors. In the final phase of our project, we are increasingly focused on such inclusive models of ethical digital competence. Therefore, it will be important in the further process of the project to develop ethically oriented materials for teaching based on our interview results and oriented to the PEAT model, which promote a digitally based treatment of inclusive communication in the classroom [26].

\section{REFERENCES}

[1] D. Connolly, "A Little History of the World Wide Web", in World Wide Web Consortium (W3C), 2000. Retreived from https://www.w3.org/History.html.

[2] S. Orgad, Media Representation and the Global Imagination, Cambridge, Malden, MA: Polity Press, 2012.

[3] D. Kerlen, Jugend und Medien in Deutschland. Eine kulturhistorische Studie (ed. by MO Rath \& G Marci-Boehncke), Beltz, Weinheim, 2005. 
Appears in: ICERI2021 Proceedings, https://doi.org/10.21125/iceri.2021.1197

[4] B. Chakravorti, and R.S. Chaturvedi, "How competitiveness and trust in digital economies vary across the world", The Fletcher School, Tufts University, 2017, retrieved from

https://sites.tufts.edu/digitalplanet/files/2020/03/Digital Planet 2017 FINAL.pdf

[5] G. Eickers and M. Rath, "Digital Change and The "Trust Deficit": Ethical and Pedagogical Implications - First results of the German research project DigitalDialog21", Conference: 14th International

Technology, Education and Development Conference, DOI: 10.21125/inted.2020.0894, 2020.

[6] J. van Dijk. The Digital Divide. Cambridge, UK: Polity Press, 2020.

[7] J. van Dijk, "Digital divide research, achievements and shortcomings", Poetics, vo. 34, no. 4-5, pp. 221-235, 2006. Retrieved from https://doi.org/10.1016/j.poetic.2006.05.004.

[8] R. Cullen, "Addressing the digital divide", Online Information Review, vol. 25 no. 5, pp. 311-320, 2001. https://doi.org/10.1108/14684520110410517

[9] M. Warschauer, "Reconceptualizing the Digital Divide", First Monday, vol. 7, no. 7, 2002. https://doi.org/10.5210/fm.v7i7.967

[10] T. Carilli, "Marginalized Voices in the Global Media Dialogue", in Oxford Research Encyclopedia of Communication, 23 Feb. 2021. Retrieved from https://oxfordre.com/communication/view/10.1093/acrefore/9780190228613.001.0001/acrefore9780190228613-e-1136.

[11] A. Bruns, "Towards Produsage: Futures for User-Led Content Production", in Proceedings: Cultural Attitudes towards Communication and Technology (F. Sudweeks, H. Hrachovec, and C. Ess, eds.), Perth: Murdoch University, 2006. pp. 275-284. Retrieved from

http://snurb.info/files/12132812018_towards_produsage_0.pdf.

[12] R. E. Park, "Human Migration and the Marginal Man", in The American Journal of Sociology, Vol. 33.6 (May 1928), 881-893, 1928.

[13] M. Bernt and L. Colini, "Exclusion, Marginalization and Peripheralization. Conceptual concerns in the study of urban inequalities", Working Paper, No 49, Leibniz Institute for Regional Development and Structural Planning, 2013.

[14] M. Fricker, M., Epistemic Injustice: Power and the Ethics of Knowing. Oxford: Oxford University Press, 2007.

[15] J. M. Billson, "No Owners of Soil. Redefining the Concept of Marginality", In Marginality, Power and Social Structure: Issues in Race, Class and Gender Analysis (R.M. Dennis, ed.), Oxford: Routledge, 2947, 2005.

[16] M. Crang, T. Crosbie, and S. Graham, "Technology, time-space, and the remediation of neighbourhood life", Environment and Planning A, vol. 39, pp. 2405-2422, 2007.

[17] M. Gilbert, M., "Theorizing Digital and Urban Inequalities: critical geographies of 'race', gender and technological capital", Information, Communication \& Society, vol. 13, pp. 1000-1018, 2010.

[18] L. Townsend, A. Sathiaseelan, G. Fairhurst, G., C. Wallace, "Enhanced broadband access as a solution to the social and economic problems of the rural digital divide", Local Economy, vol. 28 (6), pp. 580-59, 2013.

[19] W. Lemstra and W. Melody, "Cross-case analysis" In The Dynamics of Broadband Markets in Europe: Realizing the 2020 Digital Agenda (W. Lemstra and W. Melody, eds.), Cambridge: Cambridge University Press, pp. 353-384, 2015. 
Appears in: ICERI2021 Proceedings, https://doi.org/10.21125/iceri.2021.1197

[20] K. Salemink, Digital Margins: How spatially and socially marginalized communities deal with digital exclusion, University of Groningen, 2016. Retrieved from: https://research.rug.nl/en/publications/digitalmargins-how-spatially-and-socially-marginalized-communiti

[21] A. Van Deursen and J. Van Dijk, J., „The digital divide shifts to differences in usage”, New Media and Society, vol. 16, pp. 507-526, 2013.

[22] I. Mariën and J. Prodnik, "Digital inclusion and user (dis)empowerment: A critical perspective", Info, vol. 16, pp. 35-47, 2014.

[23] R. Drüeke "Verletzbarkeit durch Sichtbarkeit? Verhandlungen geschlechterpolitischer Positionen in digitalen Medien", in Anerkennung und Sichtbarkeit in Medienkulturen (T. Thomas, E. Grittmann, L. Brink, K. de Wolff eds.), pp. 173-184, Bielefeld: transcript, 2018.

[24] G. Faust, "Hair, Blood and the Nipple: Instagram Censorship and the Female Body", In Digital Environments: Ethnographic Perspectives across Global Online and Offline Spaces (U. U. Frömming, S. Köhn, S. Fox, M. Terry, eds.), pp. 159-170, Bielefeld: transcript, 2017.

[25] L. Patterson, Whiteness in contemporary feminist campaigns : Free the Nipple. College of Arts \& Sciences Senior Honors Theses, 2016.

[26] M. Rath, and M. Tannrath, "Teaching in digital societies as a topic of an ethically informed media pedagogy," in EDULEARN19 Proceedings, pp. 7507-7511, 2019. Retrieved from

10.21125/edulearn.2019.1795

[27] P. Rasi, H. Vuojärvi, and H. Ruokamo, "Media literacy education for all ages," Journal of Media Literacy Education, vol. 11, no. 2, pp. 1-19, 2019. Retrieved from

https://digitalcommons.uri.edu/jmle/vol11/iss2/1.

[28] K.E. Pearce, A. Gonzales, and B. Foucault Welles, "Introduction: Marginality and Social Media", Social Media + Society, vol. 6, no. 3, 2020. Retrieved from https://doi.org/10.1177/2056305120930413

[29] A.J. Christian, F. Day, M. Díaz, and C. /Peterson-Salahuddin, "Platforming Intersectionality: Networked Solidarity and the Limits of Corporate Social Media", Social Media + Society, vol. 6, no. 3, 2020. Retrieved from https://doi.org/10.1177/2056305120933301

[30] O. Ştefăniţă and D.-M. Buf, "Hate Speech in Social Media and Its Effects on the LGBT Community: A Review of the Current Research," Revista Română de Comunicare şi Relaţii Publice, vol. 23, no. 1, pp. 47-55, 2021. Retrieved from https://www.ceeol.com/search/article-detail?id=956976

[31] B. Chakravorti, A. Bhalla, and R. S. Chaturvedi, "The 4 Dimensions of Digital Trust, Charted Across 42 Countries”, Harvard Business Review, February 19, 2018. Retrieved from https://hbr.org/2018/02/the4-dimensions-of-digital-trust-charted-across-42-countries

[32] M. A. Devito, A. M. Walker, J. Birnholtz, K. Ringland, K. Macapagal, A. Kraus, S. Munson, C. Liang, and Herman Saksono; "Social Technologies for Digital Wellbeing Among Marginalized Communities" in Conference Companion Publication of the 2019 on Computer Supported Cooperative Work and Social Computing (CSCW '19). New York, NY, USA: Association for Computing Machinery, pp. 449-454, 2019. Retrieved from https://doi.org/10.1145/3311957.3359442

[33] M. Rath, and M. Delere, "Media Skepticism as a Prejudice - Attitudes of German Prospective Teachers towards Digital Media," in INTED 2020 Proceedings, pp. 5851 - 5858, 2020. Retrieved from http://dx.doi.org/10.21125/inted.2020.1582

[34] T. Ferfolja, and J. Ullman, "Inclusive pedagogies for transgender and gender diverse children: parents' perspectives on the limits of discourses of bullying and risk in schools", Pedagogy, Culture \& Society, 2021. Retrieved from https://doi.org/10.1080/14681366.2021.1912158 
Appears in: ICERI2021 Proceedings, https://doi.org/10.21125/iceri.2021.1197

[35] F. Krotz, "Mediatization: A concept with which to grasp media and societal change", in Mediatization: concept, changes, consequences (K. Lundby, ed.), pp. 21-40, New York: Lang, 2009.

[36] M.J. Koehler, and P. Mishra, "What happens when teachers design educational technology? The development of technical pedagogical content knowledge", Journal of Educational Computing Research, vol. 32, no. 2, pp. 131-152, 2005.

[37] G. Marci-Boehncke, "Von der integrierten zur inklusiven Medienbildung", in Medienpädagogik Herausforderungen für Lernen und Bildung im Medienzeitalter (T. Hug, ed.), pp. 49-64, Innsbruck: innsbruck university press 2018.

[38] E. Rigotti, and S. Greco Morasso, "Argumentation as an Object of Interest and as a Social and Cultural Resource", in Argumentation and Education. Theoretical Foundations and Practices (N. Muller Mirza, and A.N. Perret-Clermont, eds.), pp. 9-66, Boston, MA: Springer, 2009.

[39] O. McGarr, and A. McDonagh, "Digital Competence in Teacher Education”, Output 1 of the Erasmus+ funded Developing Student Teachers' Digital Competence (DICTE) project. 2019. Retrieved from http://hdl.handle.net/10344/7700. 